\title{
Sensitivity Analysis of Flexible Pavement Dimensioning with AASHTO (1993) Method. Part I: Effect of Subjective Variables
}

\author{
Hugo Alexander Rondón-Quintana ${ }^{1}$, Juan Gabriel Bastidas-Martínez ${ }^{2}$ and Saieth Baudilio Chaves-Pabón ${ }^{3}$ \\ ${ }^{1}$ Ph.D., Full Professor, Facultad Medio Ambiente y Rec. Naturales, Universidad Distrital Francisco José de Caldas, Colombia. \\ ORCID: 0000-0003-2946-9411 \\ ${ }^{2}$ Ph.D., Facultad de Ingeniería, Universidad Piloto de Colombia, Colombia.
}

${ }^{3}$ Ph.D., Facultad de Estudios a Distancia, Universidad Militar Nueva Granada, Colombia.

\begin{abstract}
One of the most currently used methods in the world for dimensioning flexible pavement structures is the one from American Association of State Highway and Transportation Officials - AASHTO, 1993. The authors of this article have found that design variables for this method can be classified in two groups named "objective" and "subjective". The first are established by conducting field and/or laboratory studies, while the second are defined by the designer, based on recommendations established by AASHTO. Both types of variables may present a high variability, which may impact the dimensioning of flexible pavements. This study carried out a sensitivity analysis of design variables in order to evaluate the aforementioned. The influence of subjective and objective variables will be presented in two separate papers. This paper (Part I) presents the influence of variables of a subjective nature. Additionally, a brief review of the AASHTO method is shown, where subjective and objective variables are described. A general conclusion reports that the subjective character variables evaluated have a significant impact on design thicknesses and the cost of structures, especially when subgrade resistance is lowered, and when there is an increase of traffic and temperature.
\end{abstract}

Keywords: sensibility analysis, AASHTO, design, flexible pavement, subjective variables.

\section{INTRODUCTION}

One of the most currently used methods in Colombia and in a large portion of the world for dimensioning flexible pavement structures is the one from American Association of State Highway and Transportation Officials - AASHTO [1]. This method, developed in United States on the 60s decade, had preceding versions such as those named "provisional" AASHO [2] and AASHTO [3], and the design version of ASHTO [4]. All these versions were based on empirical results obtained in real scale tests made in testing sections during two years in AASHO Road Test (Ottawa, state of Illinois). The construction of said sections began in 1956, where the first results were registered between 1958 and 1960. A great part of them can be accessed on the Highway Research Board - HRB [5].

On the other hand, AASHTO [1] version has also been modified, introducing certain mechanistic concepts (National Cooperative Highway Research Program - NCHRP [6]), under Project NCHRP 1-37a. This new AASHTO [7] version, titled Design Guide for Mechanistic-Empirical Pavements (M-E), has, among others, the following use limitations: i) There is little existing knowledge about the method and a limited access to the Mechanistic-Empirical Pavement Design software MEPDG 2008; ii) the methodology uses load spectrums as traffic variable (magnitude and frequency of expected loads during pavement design period); iii) the guide requires climatic information such as hourly temperature, precipitation, wind speed and relative humidity, among others, in order to be added to a climatic model named EICM (Enhanced Integrated Climatic Model); iv) also, it needs more detailed information in comparison to previous versions, information such as the variation of the subgrade modulus based on the soil changes in moisture and the variation of asphalt mix modulus in function of temperature, load frequencies, asphalt aging, etc. during the pavement's useful life; v) additionally, in some countries, there is neither the availability of the necessary laboratory equipment for obtaining the mechanical parameters of materials, nor the sufficient support of government institutions for the methodology's implementation. Given the aforementioned, this new version has not been extensively used at a world-wide level, and because of such reason, AASHTO [1] is still being used in countries such as Colombia.

Now, when flexible pavement structures are dimensioned through the AASHTO [1] methodology, some variables are of a "subjective", as others are of an "objective". Objective variables are those derived from studies carried out on the field and/or laboratories such as subgrade and traffic. In order to determine these, prior soil and traffic studies must be carried out, respectively. Subjective variables are those defined by the designer, based on the recommendations established by AASHTO [1] methodology, which may present magnitudes in a broad range of values. This may lead to the fact that on multiple occasions, flexible pavement structure thicknesses tend to present broad ranges of values that could be allowed in order to resist loads imposed by traffic and environmental conditions. With the purpose of evidencing the aforementioned, this study conducted a sensitivity analysis for each of the variables of the [1] method, with the goal of evaluating their influence on the dimensioning of flexible pavements, as well as for their initial cost. The influence of objective and subjective variables will be presented in two separate papers. This paper (Part I) presents the influence of subjective variables, which are the present serviceability index (PSI), reliability, layer drainage coefficients and mechanical properties of the asphalt layer. 


\section{METHODOLOGY}

Design variables will initially be described, and the values used for conducting the sensitivity analysis will be presented. First, subjective design variables will be presented, which will vary during simulations, and lastly, objective variables will be described, which must remain constant. A more detailed description of design variables may be reviewed in [8].

\section{II.I. Subjective variables}

\section{II.I.I Mechanical properties of materials}

The mechanical parameter with which the materials are characterized is resilient modulus in psi. However, when it comes to the design and dimensioning of the thickness in flexible pavement layers, these parameters are translated to structural coefficients of layers $a_{i}$, which are determined through figures presented in the AASHTO [1] design manual or in equations (1-3). When sub-index $i=1$, the structural coefficient corresponds to the asphalt surface course; $i=2$ for the unbound granular base course and $i=3$ for the unbound granular subbase course.

$$
\begin{aligned}
& a_{1}=0.184 \times \ln \left(E_{1}\right)-1.9547 \\
& a_{2}=0.249 \times \log \left(E_{2}\right)-0.977 \\
& a_{3}=0.227 \times \log \left(E_{3}\right)-0.839
\end{aligned}
$$

$E_{1}, E_{2}$ and $E_{3}$ are resilient modulus in psi of the asphaltic concrete, the granular base and the subbase, respectively. In the process of designing flexible pavements, choosing the modulus for the asphaltic concrete is generally subjective. For its definition, the method recommends using Fig. 1, which presents a broad range of values that can be chosen by pavement designers for a reference temperature $\left(T_{r e f}\right)$ of $20^{\circ} \mathrm{C}$. Based on the experience of authors and the reviewing of diverse pavement design consultantship studies, in $E_{1}$ at $20^{\circ} \mathrm{C}$ may vary between $3 \times 10^{5}$ and $4.5 \times 10^{5} \mathrm{psi}$, being a typical value $4 \times 10^{5} \mathrm{psi}$ $\left(a_{1}=0.42\right)$. In other words, in pavement design, $a_{1}$ may vary between 0.37 and 0.44 , impacting the pavement structure's thickness.

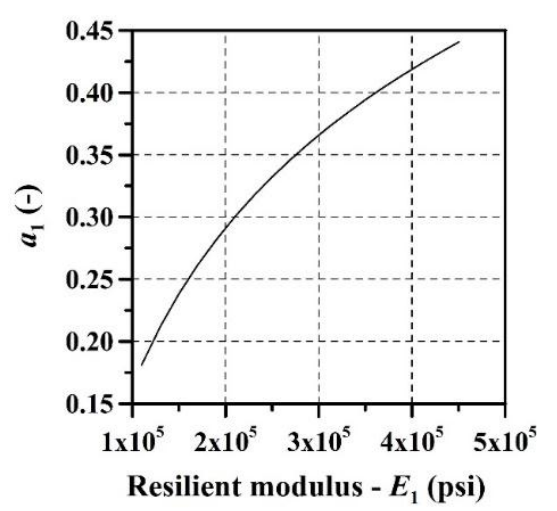

Fig. 1. $a_{1}$ and $E_{1}$ for mixing asphaltic concrete at $20^{\circ} \mathrm{C}$ [1]

On the other hand, in order to consider that $E_{1}$ changes with temperature $\left(T\right.$, in $\left.{ }^{\circ} \mathrm{C}\right)$, designers use diverse equations for obtaining this value. Some of the most used are presented in equations (4-7) [9-13]. $E_{\text {ref }}$ is the modulus obtained at $T_{\text {ref. }}$.

$$
\begin{aligned}
E_{1} & =\frac{E_{r e f}}{e^{-0.072\left(T_{r e f}-T\right)}} \\
E_{1} & =E_{\text {ref }} \times\left[1-2.2 \times \log \left(\frac{T}{T_{\text {ref }}}\right)\right] \\
E_{1} & =\frac{E_{\text {ref }}}{10^{-0.0275\left(T_{r e f}-T\right)}} \\
E_{1} & =\frac{E_{r e f}}{e^{-0.06\left(T_{r e f}-T\right)}}
\end{aligned}
$$

The process of choosing $E_{2}$ and $E_{3}$ is simpler. Designers in Colombia use the criterion of considering the minimum values of $C B R$ (Californian Bearing Ratio) demanded by the material specifications for roads of the Instituto Nacional de Vías INVIAS [14], for its determining. For the case of roadways with low (NT1) and medium (NT2) traffic volumes, the minimum CBR for bases and subbases is $80 \%$ and $30 \%$, respectively, while for high traffic volumes (NT3), said values are $95 \%$ and $40 \%$. With these magnitudes, and considering the figures recommended by [1], designers generally use $E_{2}=28000$ psi and $E_{3}=15000$ psi for NT 1 and NT2, and $E_{2}=30000$ psi and $E_{3}=17000$ for NT3.

As previously mentioned $E_{1}$ at $20^{\circ} \mathrm{C}$ may vary between $3 \times 10^{5}$ psi $\left(a_{1}=0.37\right)$ and $4.5 \times 10^{5}$ psi $\left(a_{1}=0.44\right)$, being a typical value of $4 \times 10^{5}$ psi $\left(a_{1}=0.42\right)$. These should be the modulus used for conducting the sensitivity analysis. $E_{1}$ and the thickness of the asphaltic concrete surface course are inversely proportional. Given the aforementioned, when using these three magnitudes, pavements will be dimensioned within a range where thickness will be lowest $-\mathrm{B}\left(E_{1}=4.5 \times 10^{5} \mathrm{psi}\right)$, a middle value $-\mathrm{P}$ $\left(E_{1}=4 \times 10^{5} \mathrm{psi}\right)$ and a higher value $-\mathrm{A}\left(E_{1}=3 \times 10^{5} \mathrm{psi}\right)$. Sensitivity analysis will be conducted for pavements subjected to average annual middle temperatures (TMAP) of 10, 20 and $30^{\circ} \mathrm{C}$. In order to consider the effect of temperature on mix stiffness, values presented on Table 1 will be used for $T M A P=10^{\circ} \mathrm{C}$ and $30^{\circ} \mathrm{C}$, which are the averages obtained when using equations (4-7).

Table 1. $E_{1}$ values in simulations

\begin{tabular}{|c|c|c|c|}
\hline \multirow{2}{*}{$\boldsymbol{T M A P}\left({ }^{\circ} \mathbf{C}\right)$} & \multicolumn{3}{|c|}{$\boldsymbol{E}_{\mathbf{1}}(\mathbf{p s i})$} \\
\cline { 2 - 4 } & $\mathbf{B}$ & $\mathbf{P}$ & $\mathbf{A}$ \\
\hline 10 & $8.35 \times 10^{5}$ & $7.42 \times 10^{5}$ & $5.57 \times 10^{5}$ \\
\hline 20 & $4.5 \times 10^{5}$ & $4.0 \times 10^{5}$ & $3.0 \times 10^{5}$ \\
\hline 30 & $2.45 \times 10^{5}$ & $2.18 \times 10^{5}$ & $1.63 \times 10^{5}$ \\
\hline
\end{tabular}

\section{II.I.II Loss of serviceability index, reliability and drainage coefficients}

Total loss of serviceability $\left(\triangle P S I=P_{o}-P_{f}\right)$, is a subjective index that considers the initial state of serviceability $\left(P_{o}\right)$ and final serviceability $\left(P_{f}\right)$ of pavement that will be designed and used in construction. For its determining, each state serviceability state will be evaluated in a quantitative manner by assigning a value between 0 and 5 . Once the value of 5 is assigned, it is assumed that the pavement is in perfect state of serviceability. Generally, the process begins with an initial value for 
pavements of $P_{o}$ between 4.0 and 4.5 (good state for a roadway) and the lowest value that can be tolerated by roadway users is determined before it is necessary to repair or rebuild pavement $P_{f}$. This last one varies with the roadway's level of importance (between 1.5 and 3.0, see Table 2). This means that $\triangle P S I$ may vary during the useful life of a pavement, between 1.0 and 3.0, and on that range, flexible pavement structures may greatly vary in design thicknesses. The recommended value of $P_{o}$ in the AASHO roadway experiment for flexible pavements is of 4.2 , and this will be the one used for conducting sensitivity analysis. Generally, the use of $P_{f}$ below 2.0 is not recommended, even if the traffic is low.

Table 2. Final serviceability, $P_{f}[1]$

\begin{tabular}{|l|c|}
\hline \multicolumn{1}{|c|}{ Type } & $\boldsymbol{P}_{\boldsymbol{f}}$ \\
\hline Highway & $2.5-3.0$ \\
\hline Important road & $2.0-2.5$ \\
\hline \multicolumn{2}{|c|}{ Industrial zones } \\
\hline Urban pavement (important) & $1.5-2.0$ \\
\hline Urban pavement (secondary) & $1.5-2.0$ \\
\hline
\end{tabular}

Reliability $(R)$ considers the degree of uncertainty presented during the process of estimating design variables, but mainly, it considers the traffic. Thus, it can be seen as a security factor. Table 3 presents $R$ values recommended by the design method. It is possible to observe that on this table, the designer has a broad range of choosing $R$ values in which pavement structures can significantly vary their thicknesses.

Table 3. Recommended reliability levels $R$

\begin{tabular}{|l|c|c|}
\hline \multirow{2}{*}{ Classification } & \multicolumn{2}{c|}{$\boldsymbol{R}[\%]$} \\
\cline { 2 - 3 } & Urban & Rural \\
\hline Interstate and other & $85.0-$ & $80.0-99.9$ \\
\hline Principal arterials & $80.0-$ & $75.0-95.0$ \\
\hline Collectors & $80.0-$ & $75.0-95.0$ \\
\hline Local & $50.0-$ & $50.0-80.0$ \\
\hline
\end{tabular}

Considering tables 2-3, the values of $P_{f}$ and $R$ show on Table 4 were chosen for this study. These values were established based on the author's experience and in reviewing several consultantship studies on pavement design. Additionally, these were divided, according to the manner in which they will impact design thickness, just as was done for the case of $E_{1}$ (B, $\mathrm{P}, \mathrm{A}$ are low, average and the highest thickness that will be obtained, respectively). $W_{18}$ is the traffic variable (described later).

Table 4. Recommended values for $P_{f}$ and $R$ to be used in sensitivity analysis

\begin{tabular}{|c|c|c|c|c|c|c|}
\hline \multirow{2}{*}{$\boldsymbol{W}_{\mathbf{1 8}}$} & \multicolumn{3}{|c|}{$\boldsymbol{P}_{\boldsymbol{f}}(-)$} & \multicolumn{3}{c|}{$\boldsymbol{R}(\boldsymbol{\%})$} \\
\cline { 2 - 7 } & $\mathbf{B}$ & $\mathbf{P}$ & $\mathbf{A}$ & $\mathbf{B}$ & $\mathbf{P}$ & $\mathbf{A}$ \\
\hline $5 \times 10^{5}$ & 2.0 & 2.5 & 2.5 & 80 & 90 & 95 \\
\hline $5 \times 10^{6}$ & 2.0 & 2.5 & 2.5 & 80 & 90 & 95 \\
\hline $2 \times 10^{7}$ & 2.5 & 2.5 & 3.0 & 85 & 90 & 95 \\
\hline
\end{tabular}

Drainage coefficients $\left(m_{i}\right)$ consider that in high precipitation climates, untreated granular layers of the base and subbase can be exposed to increase their water content in flexible pavements, which generates a reduction of their structural resistance. The drainage coefficient $m_{1}$ (asphaltic layer) is considered equal to 1.0, given that it assumed to be waterproof. In order to determine these coefficients in granular layers, it is initially necessary to subjectively establish, the drainage quality of granular material (see Table 5). Generally, in the process of dimensioning flexible pavements, designers tend to use drainage qualities that are "Fair" to "Very poor" in Colombia. This takes place because granular layers of the base and subbase use well-graded aggregates and are densified in such a point that air voids are scarce, which does not allow for easy evacuation of water in case it is reaches into the material. In this condition, if water comes into contact with the untreated granular layer, it will tend to retain water, experiencing its worst behavior under cyclic load. When using any of the two criteria ("Fair" to "Very poor"), pavement thickness, and mainly layers of base and subbase, can vary significantly. After defining drainage quality, it is necessary to calculate time percentage $(t)$ in the pavement structure that is exposed to moisture levels close to saturation. $t$ is calculated as a percentage relationship between the number of average rainy days in the are where the pavement structure will be built and 365 days of the year. With both parameters (drainage quality and $t$ ), drainage coefficients are calculated $m_{2}$ (base) and $m_{3}$ (subbase), using Table 6. Generally, the coefficients of both layers are assumed to be equal $\left(m_{2}=m_{3}\right)$.

Table 5. Drainage Quality [1]

\begin{tabular}{|c|c|}
\hline Drainage Quality & Water removed within \\
\hline Excellent & 2 hours \\
\hline Good & 1 day \\
\hline Fair & 1 week \\
\hline Poor & 1 month \\
\hline Very poor & Water will not drain \\
\hline
\end{tabular}

Table 6. Recommended values for $m_{i}$ to be used in granular bases and subbases [1]

\begin{tabular}{|c|c|c|c|c|}
\hline \multirow{2}{*}{$\begin{array}{c}\text { Drainage } \\
\text { Quality }\end{array}$} & \multicolumn{4}{|c|}{$t$} \\
\cline { 2 - 5 } & Less than 1\% & $\mathbf{1 - 5 \%}$ & $\mathbf{5 - 2 5 \%}$ & $\mathbf{7 2 5 \%}$ \\
\hline Excellent & $1.40-1.35$ & $1.35-1.30$ & $1.30-1.20$ & 1.20 \\
\hline Good & $1.35-1.25$ & $1.25-1.15$ & $1.15-1.00$ & 1.00 \\
\hline Fair & $1.25-1.15$ & $1.15-1.05$ & $1.00-0.80$ & 0.80 \\
\hline Poor & $1.15-1.05$ & $1.05-0.80$ & $0.80-0.60$ & 0.60 \\
\hline Very poor & $1.05-0.95$ & $0.95-0.75$ & $0.75-0.40$ & 0.40 \\
\hline
\end{tabular}

The $m_{2}=m_{3}$ values chosen for the analysis were 0.9 and 0.7 . The first value is typical for granular layers with a fair drainage quality and $t=15 \%$ (see Table 6 ). The second value is chosen by the designer for the same $t$, however, assuming a poor drainage quality. In general, very poor drainage quality is not chosen in pavement design. Just as for $P_{f}$ and $R, m_{i}$ values were divided according to the way in which they will impact pavement thickness $\left(m_{2}=m_{3}=0.9\right.$ for conditions B, P and 0.7 for A). 


\section{II.II Objective variables}

\section{II.II.I Traffic}

The traffic $\left(W_{18}\right)$ is characterized through the number of equivalent single axle loads number (ESALs) of 18 kips (8.2 tons). The following values were chosen for conducting simulation: $W_{18}=5 \times 10^{5}, 5 \times 10^{6}$ and $2 \times 10^{7}$. The first two are limits established by INVIAS [14] for NT1 $\left(W_{18}<5 \times 10^{5}\right)$ and NT3 $\left(W_{18}>5 \times 10^{6}\right)$.

\section{II.II.II Subgrade}

Subgrade is characterized through its resilient modulus $\left(E_{s u b r}\right)$. Given that in practice, this variable's estimation is experimentally difficult to attain, be it because of costs, lack of equipment or finding the correct definition of stress trajectories, what is traditionally done with the variable, is to correlate it to the $C B R$ value through equation (8).

$$
E_{\text {subr }}=1500 \times C B R(\mathrm{psi})
$$

The values taken from $C B R$ subgrade for conducting simulations were $3 \%$ and $10 \%$. Using equation (8) recommended by [1], the magnitudes of $E_{\text {subr }}$ are $4500 \mathrm{psi}$ and 15000 psi, respectively. Values lower than $3 \%$ were not chosen, given that there was a requirement for improving the subgrade.

\section{II.III. Costs analysis}

Once the sensitivity analysis has been carried out, the cost per $\mathrm{m}^{2}$ for each of the dimensioned structures was estimated. This was only considered in cost analysis for materials (including transport, extension, compaction, labor force and equipment). Reference unit prices for calculations were the ones recommended by Instituto de Desarrollo Urbano - IDU [15] for the city of Bogotá D.C. Dollar price is for February of 2020.

\section{RESULTS OF SIMULATIONS}

Simulation results were presented in Figs. 2-6. $h_{1}$ refers to the thickness of the asphalt layer. With the purpose of evaluating the results of figures, base thicknesses $\left(h_{2}\right)$ and subbase $\left(h_{3}\right)$ were kept constant for each analyzed temperature, depending on the subgrade and the traffic (see Table 7). It is boldly observable in Fig. 2, that there is an increase in $h_{1}$ when there is an increase of TMAP and $W_{18}$, and a reduction of $C B R$ in the subgrade.

Table 7. Values of $h_{2}$ and $h_{3}$

\begin{tabular}{|c|c|c|c|c|c|c|}
\hline \multirow{3}{*}{$\begin{array}{c}C B R \\
(\%)\end{array}$} & \multicolumn{6}{|c|}{$W_{18}$} \\
\hline & \multicolumn{2}{|c|}{$5 \times 10^{5}$} & \multicolumn{2}{|c|}{$5 \times 10^{6}$} & \multicolumn{2}{|c|}{$2 \times 10^{7}$} \\
\hline & $\begin{array}{c}h_{2} \\
(\mathrm{~cm})\end{array}$ & $\begin{array}{c}h_{3} \\
(\mathrm{~cm})\end{array}$ & $\begin{array}{c}h_{2} \\
(\mathrm{~cm})\end{array}$ & $\begin{array}{c}h_{3} \\
(\mathrm{~cm})\end{array}$ & $\begin{array}{c}h_{2} \\
(\mathbf{c m})\end{array}$ & $\begin{array}{c}h_{3} \\
(\mathrm{~cm})\end{array}$ \\
\hline 3 & 15 & 30 & 20 & 40 & 30 & 50 \\
\hline 10 & 10 & 10 & 15 & 20 & 15 & 30 \\
\hline
\end{tabular}
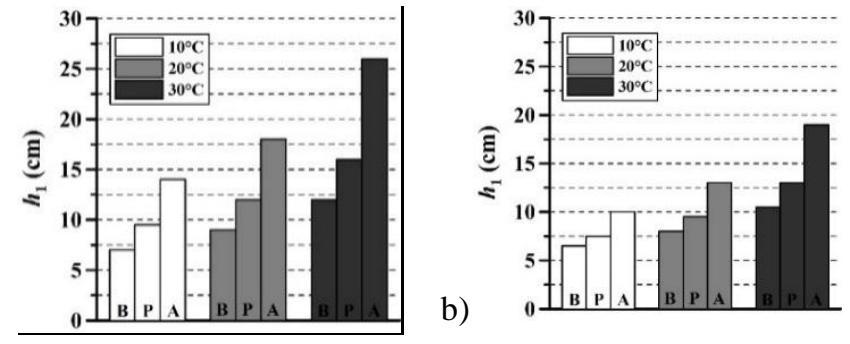

c)
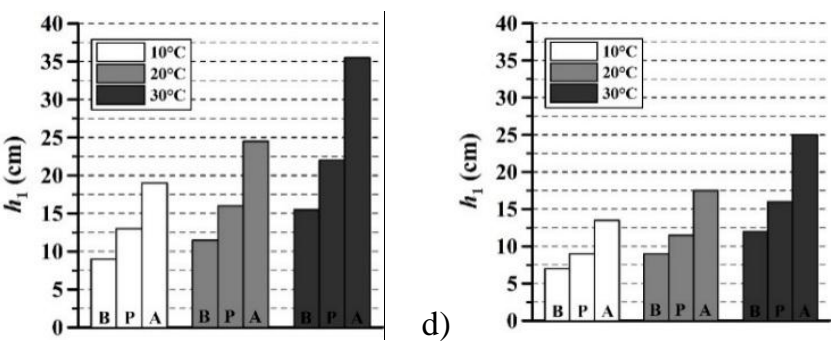

e)
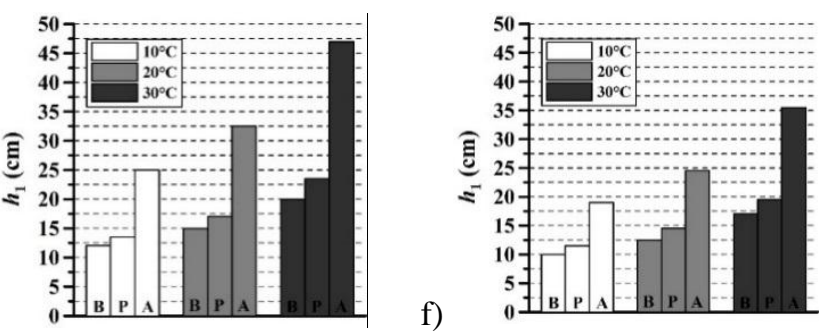

Fig. 2. a) $W_{18}=5 \times 10^{5}, C B R=3 \%$; b) $W_{18}=5 \times 10^{5}, C B R=10 \%$; c) $W_{18}=5 \times 10^{6}, C B R=3 \%$; d) $W_{18}=5 \times 10^{6}, C B R=10 \%$; e)

$W_{18}=2 \times 10^{7}, C B R=3 \%$; f) $W_{18}=2 \times 10^{7}, C B R=10 \%$

Fig. 3 shows the maximum variability range possible for $h_{1}$ (difference of thicknesses in the asphaltic layer between condition $\mathrm{B}$ and $\mathrm{A}$, named $\Delta \mathrm{A}-\mathrm{B}$ ) for each $W_{18}$ analyzed. Fig. 4 shows the influence of said variability in terms of costs. A notorious variability in $\Delta \mathrm{A}-\mathrm{B}$ can be observed (both in $h_{1}$ thickness as in the cost of dimensioned structures) when the values of TMAP and $W_{18}$ increase and the subgrade's $C B R$ is reduced. In flexible pavement design, $\triangle \mathrm{A}-\mathrm{B}$ could vary between $3.5 \mathrm{~cm}$ (approximate cost variation of $5.4 \mathrm{US} \$ / \mathrm{m}^{2}$ ) and $27 \mathrm{~cm}$ (approximate cost variation of $41.9 \mathrm{US} \$ / \mathrm{m}^{2}$ ) for the case where variability range is lower $\left(T M A P=10^{\circ} \mathrm{C}, W_{18}=5 \times 10^{5}\right.$, $C B R=10 \%)$ and higher $\left(T M A P=30^{\circ} \mathrm{C}, W_{18}=2 \times 10^{7}, C B R=3 \%\right)$, respectively. In other words, in the moment of dimensioning flexible pavements, the range of thicknesses and costs for structures is very broad.

a)

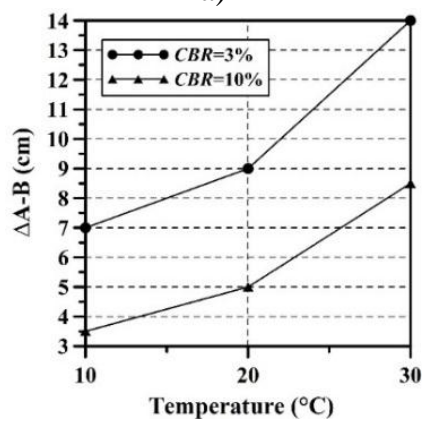

b)

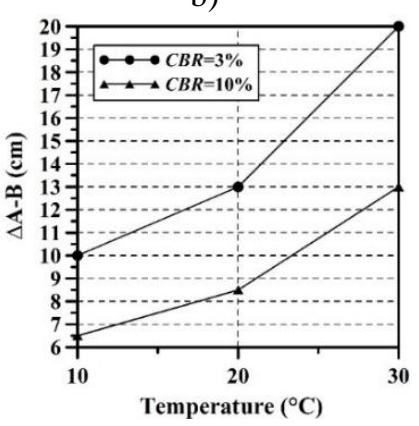




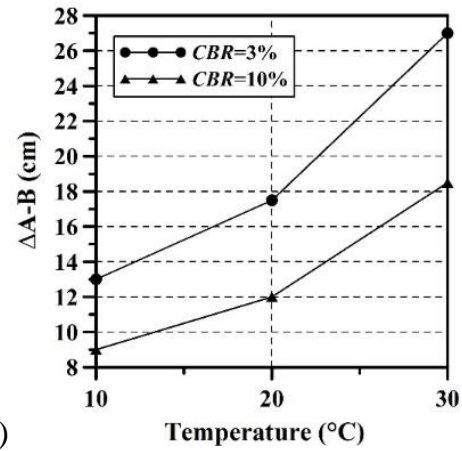

Fig. 3. Variability range of $\Delta \mathrm{A}-\mathrm{B}$ para a) $W_{18}=5 \times 10^{5}$; b) $W_{18}=5 \times 10^{6}$; c) $W_{18}=2 \times 10^{7}$

a)
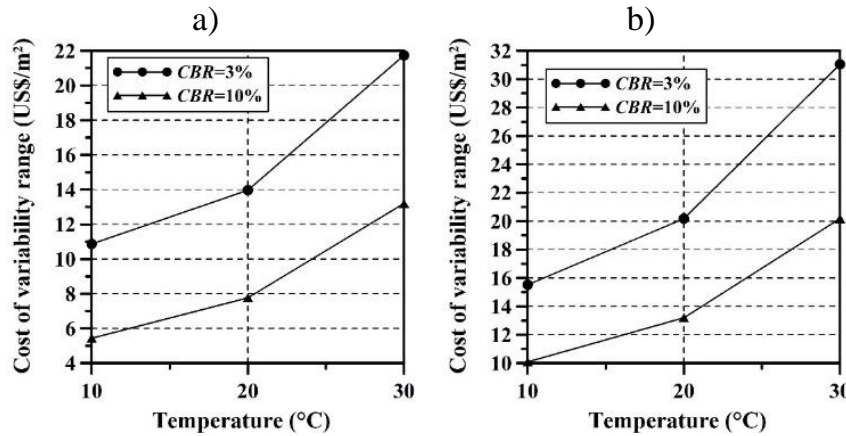

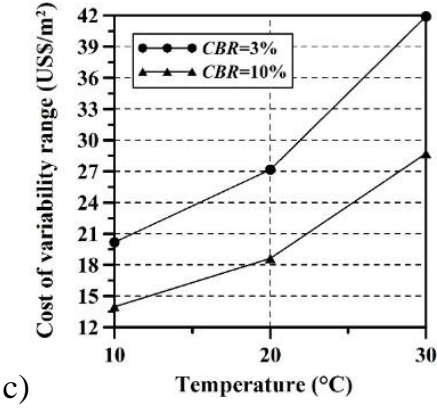

Fig. 4. Cost associated to variability range of $\triangle \mathrm{A}-\mathrm{B}$ for a) $W_{18}=5 \times 10^{5}$; b) $W_{18}=5 \times 10^{6}$; c) $W_{18}=2 \times 10^{7}$

On the other hand, just as was previously mentioned, pavement designers generally use values assigned for condition P. With the purpose of comparing this condition with conditions $\mathrm{B}$ and A, Figs. 5-6 graph the difference of thicknesses $h_{1}$ between A and $\mathrm{P}(\Delta \mathrm{A}-\mathrm{P})$ and between $\mathrm{B}$ and $\mathrm{P}(\Delta \mathrm{B}-\mathrm{P})$, respectively. Fig. 5 shows a notable increase of $\triangle \mathrm{A}-\mathrm{P}$ as there is an increase of TMAP and $W_{18}$, and a reduction of $C B R$ in the subgrade. In flexible pavement design, $\triangle \mathrm{A}-\mathrm{P}$ could vary between $2.5 \mathrm{~cm}$ (approximate cost variation of $3.9 \mathrm{US} \$ / \mathrm{m}^{2}$; increase in cost for condition A with relation to a $\mathrm{P}$ of $20.5 \%$ ) to $23.5 \mathrm{~cm}$ (approximate cost variation of $36.5 \mathrm{US} \$ / \mathrm{m}^{2}$; increase in the cost of condition A with relation to a $\mathrm{P}$ of $55.7 \%$ ) for the case where variability range is lower $\left(T M A P=10^{\circ} \mathrm{C}, \quad W_{18}=5 \times 10^{5}\right.$, $C B R=10 \%)$ and higher $\left(T M A P=30^{\circ} \mathrm{C}, W_{18}=2 \times 10^{7}, C B R=3 \%\right)$, respectively. For the case of $\triangle \mathrm{B}-\mathrm{P}$, the differences are lower and there is no clearly defined trend. The maximum difference reported between both conditions is of $-6.5 \mathrm{~cm}$ (Approximate cost variation of $10.1 \mathrm{US} \$ / \mathrm{m}^{2}$; cost reduction of condition $\mathrm{B}$ with relation to a $\mathrm{p}$ of $18.9 \%$ ). These lower magnitudes of $\Delta \mathrm{B}$ $\mathrm{P}$ in comparison to $\triangle \mathrm{A}-\mathrm{P}$ are given because designers generally

assume magnitudes for subjective variables in $\mathrm{P}$ that are very similar to those of condition B, given that they tend to dimension using the main criterion of construction of less expensive structures.

a)

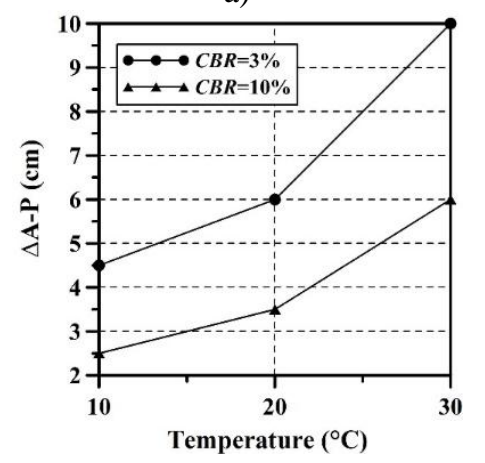

b)

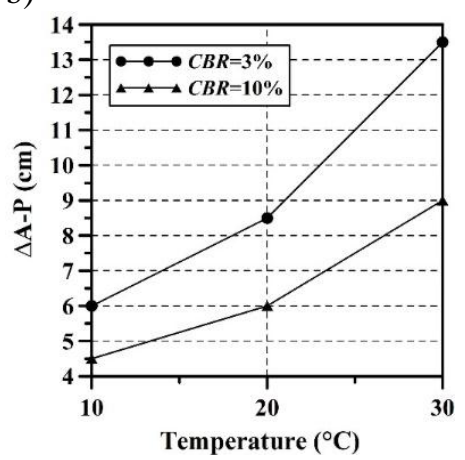

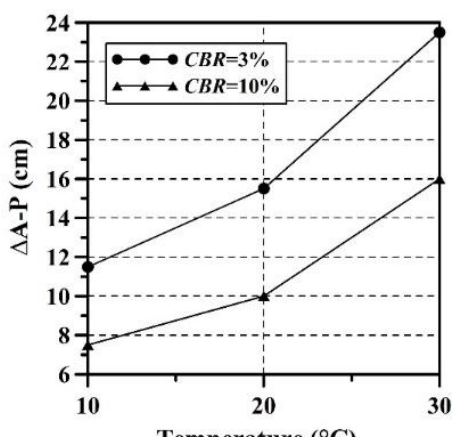

Fig. 5. $\Delta \mathrm{A}-\mathrm{P}$ for a) $W_{18}=5 \times 10^{5}$; b) $W_{18}=5 \times 10^{6}$; c) $W_{18}=2 \times 10^{7}$ a)

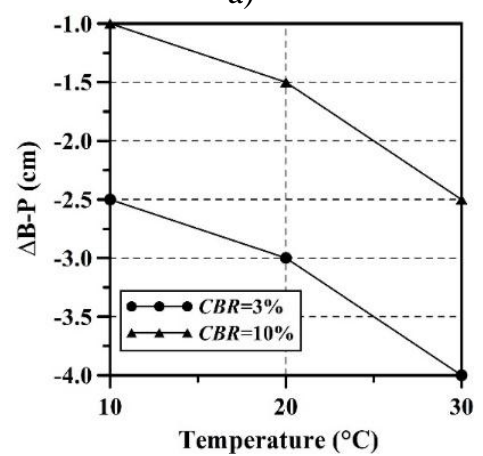

b)

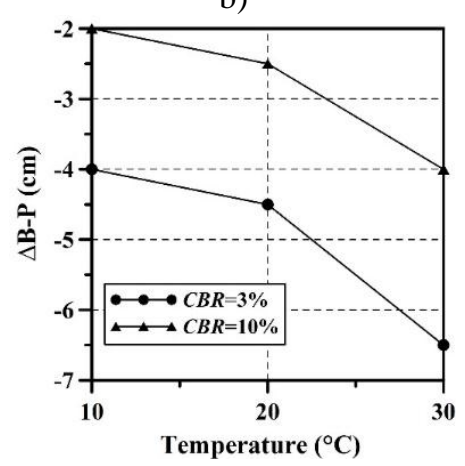

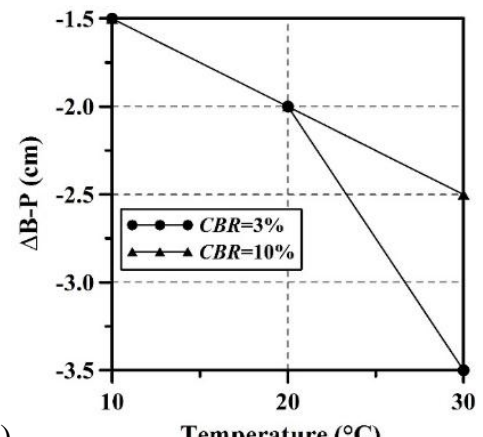

c)

Temperature $\left({ }^{\circ} \mathrm{C}\right)$

Fig. 6. $\Delta$ B-P for a) $W_{18}=5 \times 10^{5}$; b) $W_{18}=5 \times 10^{6}$; c) $W_{18}=2 \times 10^{7}$ 


\section{CONCLUSIONS}

This study conducted a sensitivity analysis of each of the "subjective" variables in the AASHTO [1] method, with the purpose of evaluating its influence in dimensioning of flexible pavements and their initial cost. The following are the main conclusions.

- The range of possibilities the designer is exposed to at the moment of choosing the most appropriate values for $E_{1}, P_{f}, R$ y $m_{i}$ have a significant impact in design thicknesses and costs for structures, especially when the subgrade's $C B R$ is reduced and when the temperature and the traffic increase.

- For the condition in which the impact of subjective variables is lower $\left(T M A P=10^{\circ} \mathrm{C}, W_{18}=5 \times 10^{5}, C B R=10 \%\right)$, the thickness of the asphalt layer may vary in its designs in $3.5 \mathrm{~cm}$. which entails an approximate variation in the cost of structures of $5.4 \mathrm{US} \$ / \mathrm{m}^{2}$. However, for the condition of higher impact $\left(T M A P=30^{\circ} \mathrm{C}, W_{18}=2 \times 10^{7}, C B R=3 \%\right)$, said design thickness may vary in $27 \mathrm{~cm}$, entailing an approximate cost variation of structures of $41.9 \mathrm{US} \$ / \mathrm{m}^{2}$. In other words, in the process of designing flexible pavements, thickness can increase between one or other condition in a measure of 7.71 times, while cost can increase 7.76 times.

- For the case of $T M A P=10^{\circ} \mathrm{C}, W_{18}=5 \times 10^{5}$ and $C B R=10 \%$, when a designer defines subjective variables, assuming high safety factors (where layer thicknesses will be the highest; named condition $\mathrm{A}$ in this study), the asphalt layer in designs can be 2.5 times superior in relation to the condition of generalized definition for said variables (where layer thicknesses are those typically obtained in pavement design; named condition $\mathrm{P}$ in this study), generating an approximate increase in structure cost of $20.5 \%$. For $T M A P=30^{\circ} \mathrm{C}$, $W_{18}=2 \times 10^{7}$ and $C B R=3 \%$, the thickness in the asphalt layer can be $23.5 \mathrm{~cm}$ superior, entailing an approximate increase in the cost of structures of $55.7 \%$.

- When a designer defines subjective variables assuming the condition where layer thicknesses will be the lowest possible (named condition B in this study), the asphaltic layer's thickness does not vary with a clearly defined trend with relation to $T M A P, W_{18}$ and $C B R$, when being compared to condition $\mathrm{P}$. In the process of designing the variability of the asphaltic layer's thickness in $B$ with relation to $P$, it can vary between -1.0 and $-6.5 \mathrm{~cm}$, which represents a maximum cost reduction of condition $\mathrm{B}$ in relation to $\mathrm{P}$ of $18.9 \%$.

- The lowest differences between $\mathrm{P}$ and B compared with those obtained between $\mathrm{P}$ and $\mathrm{A}$ are because designers tend to dimension flexible pavement structures using the main construction criterion of building less costly structures on a short term. However, designing these roadway structures has a high degree of uncertainty when variables are estimated (changing conditions on the soil, traffic, climate, mechanical properties of materials, among others) and in this regard, it is possible for them to be sub-dimensioned when: i) conditions $\mathrm{P}$ and $\mathrm{B}$ are being used; ii) when temperature increases and becomes high; iii) the magnitude and ESALs that circulate through the roadway being high; iv) resistance of the subgrade is lowered or is low. Results obtained in the sensitivity analysis of this study evidence this aspect.

\section{ACKNOWLEDGEMENTS}

The authors thank the Universities related to the development of this study: U. Distrital Francisco José de Caldas, U. Piloto de Colombia and U. Militar Nueva Granada.

\section{REFERENCES}

[1] AASHTO. AASHTO Guide for Design of Pavement Structures. American Association of State Highway and Transportation Officials, 1993, Washington, DC.

[2] AASHO. Interim guide for the design of flexible pavement structures. American Association of State Highway Officials, 1961, Washington, DC.

[3] AASHTO. AASHTO Interim Guide for Design of Pavement Structures, American Association of State Highway and Transportation Officials, 1972, Washington, DC.

[4] AASHTO. Guide for Design of Pavement Structures. American Association of State Highway and Transportation Officials, 1986, Washington, DC.

[5] HRB. The AASHO Road Test. Report 5: Pavement Research; Report 6: Special Studies; Report 7: Summary Report; Special Reports 61E, 61F, and 61G, Highway Research Board, 1962, Washington, DC.

[6] NCHRP. Mechanistic-Empirical Design of New and Rehabilitated Pavement Structures, draft report, NCHRP Project 1-37A, National Cooperative Highway Research Program, National Research Council, 2004, Washington, DC.

[7] AASHTO. Mechanistic-Empirical Pavement Design Guide - A Manual of Practice. American Association of State Highway and Transportation Officials, 2008, Washington, DC.

[8] Rondón, H A, and Reyes, F A. Pavimentos: Materiales, Construcción y Diseño [Pavements: Materials, Construction and Design], Ed. ECOE, First Edition, Bogotá D.C., Colombia, 2015, 624 p.

[9] Baltzer, S and Jansen, J M, Temperature correction of asphalt-moduli for FWD measurements, Proceeding of the 4th International Conference on the Bearing Capacity of Roads and Airfields, Minneapolis, MN, 1994, 753-768.

[10] Loizos, A, Papavasiliou, V, Plati, C and Tsaimou, C, Temperature correction of HMA moduli base on in situ pavement data, Proceeding of 6th International Conference "Bituminous Mixture and Pavement", Thessaloniki, Greece, 10-12 June 2015.

[11] Stubstad, R N, Baltzer, S, Lukanen, E O and ErtmanLarsen, H J, Prediction of AC Mat temperature for routine load/deflection measurements, Proceeding of the 4th International Conference on Bearing Capacity of Roads and Airfields, Minneapolis, 1994, Minnesota, USA.

[12] Jung, F W, Interpretation of deflection basin for realworld materials in flexible pavements, Research Report RR-242, Ontario Ministry of Transportation, Research and Development Branch, 1990, Ontario, Canada. 
International Journal of Engineering Research and Technology. ISSN 0974-3154, Volume 13, Number 5 (2020), pp. 879-885

(C) International Research Publication House. https://dx.doi.org/10.37624/IJERT/13.5.2020.879-885

[13] Kim, Y R, Hibbs, B O, and Lee, Y, Temperature correction of deflection and backcalculated asphalt concrete moduli, Transportation Research Record, 1473, 1995, 55-62.

[14] INVIAS - Instituto Nacional de Vías. (2013). Especificaciones generales de construcción de carreteras, Bogotá D.C., Colombia.

[15] IDU - Instituto de Desarrollo Urbano. Precios Unitarios de Referencia 2019-II + Mano de Obra 2020. Disponible en:

https://www.idu.gov.co/page/siipviales/economico/port afolio. Consultado el 3 de febrero de 2020. 